Mr. T. H. Wavish (Disabled Drivers' Association):

Mr. Chairman, we have heard quite a lot about the needs of users of the normal type of wheelchair. Now our Association finds that there is a considerable need in the case of the very badly disabled for the electrically driven chair, such as we were shown in the Swedish slides. We do feel that a consultant should be able to prescribe one of these chairs as being necessary for the patient just as much as prescribe the ordinary chair or tricycle.

\title{
ChaIRMAN:
}

Thank you. We have had a very fruitful discussion and we have to close the morning session's discussion now. But before doing so I should like to thank all the speakers who have given us these excellent papers and all who have taken part in the discussion. I think everyone will go home with some thoughts and inspiration and I am quite sure that this is a good beginning.

I shall now ask Dr. Dalzell-Ward to take the Chair for the next session.

\section{Discussion on Design and Manufacture}

Chairman (Dr. A. J. Dalzell-Ward, M.R.C.S., L.R.C.P., D.P.H., F.R.S.H., Medical Director, The Central Council for Health Education):

Ladies and Gentlemen, before I introduce the two opening speakers for this session, I should like to thank the organisers of this Conference for their kindness in inviting me to take the Chair for this part of the programme. The part to be played by the various organisations has been well established, and also the part that the education agencies have to play in this particular kind of work.

Now to open the discussion this afternoon we have two eminent speakers who have devoted all their working lives to technologies which are fundamental to the special problems of wheelchairs.

Mr. Bunyan, who is going to be the first speaker, is well known to doctors, especially to doctors who served in the Armed Forces during the recent war, as the inventor who developed the system which was of enormous benefit to humanity for the continuous irrigation of burns. He tells me that he himself was the founder of the Medical Engineering Development Trust, which is, at least in part, an answer to the speaker who recently said that we have no medical engineering research organisation in this country. We do not have it at university level certainly, but this is an independent organisation financed by public subscription. And Mr. Bunyan in fact employs six engineers on research in the laboratory at Bournemouth, and if anyone originates a new idea in medical work, mainly appliances, and thinks that it could be developed, he can take the idea along to him and they can develop it and make a prototype.

Mr. Bickerstaff is Managing Director of Richards, Son and Allwin, and is connected with various other companies in addition to the company mentioned here. He tells me he is also interested in Tan-Sad Holdings, and I suggest that that firm is also a producer of vehicles which are of a kind which have certain characteristics in common with the kind of production methods and materials we are considering. Mr. Bickerstaff has been a production engineer all his life and he wanted me to say that he started on the shop floor and that from the point of view of the manufacturer he knows the job right from the bottom upwards.

Now I am going to ask the two speakers to give us their opening statements, and I am then going to invite discussion.

Mr. John Bunyan (Director, Medical Engineering Development Trust):

Having listened to what has gone before, it is quite obvious that there is a need for 
the Medical Engineering Development Trust. We have been well aware of the appalling problem facing inventors of any practical medical idea not only in this country but all over the world. If one has a practical idea it is quite impossible to get any financial support to go ahead; because it is not a question of using white rats or of injecting some chemical, we do not rate as a medical research body, with most of the other medical research foundations.

This is a world-wide problem. I experienced much pain and trouble over thirty years in having to work on my own ideas at my own cost, and very great cost, not only to myself but to my wife. And I eventually came to the conclusion that the only way to overcome this was to found a non-profit-making trust and try to get public support, and then go ahead and have an engineering shop and make prototypes of any good idea. By good idea I mean a medical invention that would first of all meet a definite need, not just some idea of one particular surgeon. It must be practicable and it must have commercial potential, because if it is not something that somebody can make a profit on, a company is jolly well not going to make it, however much the patient needs it.

Now what are we doing about the wheelchair? I am not going to enter into any discussion about the wheelchair itself. We have heard about it almost ad nauseum all day. I should like to tell you how we propose to tackle the problem of wheelchairs. For the problem to fit in with our way of doing things we would say first of all that we are not going to read the literature to find out what so many have done before in the way of research. We are not going to see what anyone else has done. In the beginning we are going to get people who use wheelchairs and have them down at Bournemouth. We have got a day hospital building and we have got an orthopaedic nursing sister, and we are going to watch people use their wheelchairs and we are going to see what can be done, knowing nothing about it from the point of view of what has gone before.

We want to canvass the idea of a modular system. The idea would be to have a basic framework and have all the bits and pieces as required, not just the one thing which would be terribly heavy, but a rational modular system that will produce a light easy chair that can be fitted to each individual need. We may, of course, be trying to find a philosopher's stone. The next speaker can tell us that, but first we are going to see what the problem is. Our engineers are going to watch the patient and see at first hand what the problem is. We shall try it simply, and when we think we have found the solution we shall have a little model which can be done quite simply in plastic. We are then going to develop the models into full-size prototypes.

Then having done that, if that works, we shall then find a manufacturer with whom we can work on the production prototype. He will know all the pieces that he can get off the shelf and which are easy to obtain, for what we want to make. The final prototype is a combined effort between us and the manufacturer.

We feel that there are certain things that could be done in the wheelchair field that are very important. I remember in Boston, Massachusetts, some years ago seeing some limbless or paralysed people who were in wheelchairs most of the year, and I thought how terrible it is to be condemned always to sit down. I thought then: can we not make a wheelchair which will enable people to stand up at parties say, behind a bench? Will that not make a big difference to them? We have designed such a vehicle which I think would work.

I have already spoken about a modular system. We should try to find out what everyone wants and then try to get down to a common denominator. At the moment, from what I can see, the wheelchair business has really got into a variation on a common theme. There has been no real new thinking, and I should like to tackle this problem by looking at it afresh with new eyes, with no tradition behind me, and see if our team can produce something well worth while.

Another thing in the development of wheelchairs is the question of suitable wheelchairs for the underdeveloped countries. I went to Uganda not long ago and came to the conclusion that the sophisticated European type of chair was not suitable. The African has a genius for smashing things, and it means that we have got to design a wheelchair 
that will not, if possible, be liable to be smashed up. If we can work on this problem and help all the foundations interested, and be quite independent, and just work with the manufacturers but not under them, then I think we shall be able to do something about it.

Mr. J. H. Bickerstaff (Managing Director, Richards, Son and Allwin Co. Ltd.):

I began to wonder, as I prepared a few notes so that I had a little guidance, how many of the previous speakers had been looking over my shoulder, because so much of what has been said is down here. And therefore you have got all the history as to how the need came about and now have come to how it happened that we were in the invalid wheelchair business at all, which we have been for over fifty years. We come back to the basic essentials, instead of dealing with something that is not necessarily fact, and say how does the manufacturer in any case get interested in this sort of business? Well, he quite obviously gets interested in this sort of business initially because there happens to be a need for the product. Then the functional necessities of the appliance have certain standard requirements to be satisfied too. There are the questions of weight and height-you have heard all this before.

Then, as you know, one type of wheelchair will not suit all needs. They really fall into two main categories: there is the self-propelled chair and the chair that has to be pushed or pulled. This problem just does not finish. From long experience I will tell you where our research comes from in this; it is the user who is the most important member as far as I am concerned, and that is what puts us in this business.

So we have this on the drawing-board in its original form and then we have to try and think of all the variations that need to go into the wheelchair, and some of them are just quite impossible. I think Mr. Denly made the point earlier about whether the wheel should not be at the back instead of the front. And certainly these problems became self-evident when chairs were ordered by the Ministry of Health. I would go as far as to say that the greatest stimulus in this business came with the advent of the Ministry of Health, because this is where quantity started entering into the picture and people started giving this far more thought.

Having done all this, you start to say, 'Well, does this sort of product interest us and does it fit in with the rest of our organisation? Is the plant right? Is the labour right? Is it the sort of product that we could mould into our organisation?' And I may say of course that we are fairly well-established in the baby carriage industry, so these wheeled vehicles carry many of the same sort of parts. It looked right to us and of course at first it was going very slowly indeed, because one must remember that earlier on it was only the more affluent members of society who could either buy or hire this device; it was a very small industry. But with the advent of the Ministry of Health some impetus came into this.

So what do we consider when we put this thing on the drawing-board? First is the safety angle. Secondly we have to make it strong enough to give a long life. It has to be compact enough as we already know, folding for storage and transportation, and it has to be reasonably priced.

There is no need to remind you that in this product, like so many others, the motor car has greatly influenced what is required. I suppose in thinking along these lines, before one ever started to think of manufacturing difficulties, our greatest problem is how to fabricate a standard chair which meets the requirements of individuals who are incapacitated to varying degrees, and very wide these degrees of incapacity are. There could be a case made that each chair should be custom-built or tailor-made. If there were standard measurements like there are for a suit, I am quite certain that this would be some help. Mind you, when you start tailor-making or making chairs to measure and you start putting specialised engineering skills into a product, you have got to be sure that the labour force is there together with the demand.

I am going to suggest that if you pursued this you would find that you would not get delivery because the people are not there with the specialised skills to make this sort of 
thing. I would concede there that the answer might seem to be to have the individual specialist and I think there is a good case for this, but this is certainly not the way it would suit our form of production.

We gradually developed this transit type of wheelchair and we make about twenty or thirty other types of invalid wheelchairs.

Just a word or two about manufacturing. We need a degree of standardisation if we are going to overcome the delivery problem at all. So before we have any orders, before we know what the individual needs are, we must put thousands of parts into pre-production, parts which can be used as a bank from which to build to individual requirements. This, together with the varying accessories, is the way we go about the production angle. Unfortunately no statistics are available to say who is going to be crippled with what in the next few weeks. How can you cater for something when you do not know what will be required? Therefore one uses all the modern techniques, and the whole time techniques are changing and methods of production are changing. We are really here right in the midst of a second Industrial Revolution which is going fifty times as fast as the last. You therefore have to keep in stride with the changes in manufacture, and it is a very difficult thing.

I suppose our greatest problem is how we are going to provide for some standard wheelchair which is reduced in weight and is of at least equal strength and without any extra price. This is not an easy one to answer. I suppose all our information will, as it has in the past, have to come from the user. This is the way our business is conducted. I do not have to tell you probably that every other week I have someone sending me an idea of something that he has patented or made an approach about, which he believes will be of interest to me. Together with the official medical officers we look at these ideas from time time and quite frankly I think some progress has been made but a lot more is necessary.

\section{Chairman:}

Thank you very much. Well now, I should like to invite delegates to contribute to the discussion.

\section{Mr. LouIs:}

My impression was that part of the need for this meeting arose out of the discussion which started in regard to wheelchairs as to whether there was a lowest common denominator of all disabled people. It was felt that this could be discussed, and the problem at the time was that there was really a need for the highest common factor for a series of chairs required by disabled people segregated according to disease but which was yet a production possibility on the basis of quantity. There was certainly a need to establish the highest common factor, and on that basis from the quantities mentioned of wheelchairs issued every year, I should think there is at least a case for separating and for designing two, three or possible four special purpose chairs which in themselves still represent economic batch quantities. This is currently established technique. The thought has occurred to us as to whether this current system of tendering is in fact the ideal. The ideal is a system which allows the manufacturer to design and tool up for special purpose chairs so that he has a sufficiently long run to pay for the plant investment and the equipment. The good manufacturer is handicapped by having to cater for requirements annually. I think-I do not know what the system is in fact, but I think a better system would be to agree on a special purpose chair which would have a run of certainly a number of years.

\section{Mr. L. D. LEEDS:}

The Ministry of Education and Local Authorities have found that better procedures of tendering are producing better buildings. It is a question of negotiations in bulk and in relation to development and it may well be found that similar procedures could replace the system of tendering in the Ministry of Health and that it might be better. 


\section{ChaIRMAN:}

Would you like to comment on that, Mr. Bickerstaff?

Mr. J. H. BickerstafF:

Possibly you did not all hear that. The gentleman down here implies that we would possibly do better by following the methods of the Ministry of Education on tendering. I think you are quite wrong, sir. The Ministry of Health in fact do use all these facilities, and tendering is a very serious and searching business, as I well know, and contracts are only awarded on the basis of previous experience, quality and price.

It really follows Dr. Agerholme's comment regarding armrests and whether or not they should be detachable. I think no one mentioned at all that one of the prime reasons that an armrest was made detachable was to enable the occupant to take the armrest off so that he could pick up whatever he had dropped on the floor. That was why it was invented.

\section{Mr. JoHn BunYan:}

One thing that I had not time to mention before and that was arising from what people said earlier about the need to have an engineer and a laboratory working on these problems. The need is to have a medical engineer working on this problem. There is an enormous difference in the discipline of engineering and the discipline of medicine, and so you need the medical engineer. Just to make this point clearer. We had a man come from the north with the most beautifully prepared drawings for a patient lift which was going to lift the patient out of bed. It was a combination of the usual thing-a doctor going to an engineer and asking him to do something. They were beautiful drawings and it was wonderful engineering, but utterly useless for any hospital or domestic use. It would have been ideal for lifting an engine out of a lorry, but useless for lifting a patient out of bed. I am quite certain, the more I see of medical engineers that we must get the discipline in it right, and we must only get people who are trained in it.

\section{Mr. S. KenNoway:}

May I follow that? I would agree also with what Dr. Agerholme said earlier, that any form of research in this area must be founded on very close contact with clinical conditions. I personally think that one makes a mistake if the laboratory is somewhere away from the hospital-five miles is too far. Of course, we are a long way away from having medical engineers. Just as fifteen years ago we had no chemical engineers and we now have chemical engineering courses in the universities. However, some did postgraduate work and that was how they became chemical engineers. I think nowadays it is the same thing for medical engineers. They have to do engineering in a medical environment. This is one step by which it can be done. The other step is clearly to follow the biological engineering courses that are now being established in some of the universities with close collaboration with the engineering and medical faculties. The closer clinicians can get to such skills, the less likelihood there is of these schools remaining purely academic.

\section{Dr. M. AgERHOLME:}

There is one other point I should like to air this afternoon. The last speaker definitely brought up one major source of unhappiness concerning these people working on wheelchairs and other equipment, and that is that under the National Health Service there is nobody who is defined as being a medical engineer. The position has no name and no salary scale, and therefore no opportunity for advancement. It means that anybody in the medical world who wants any engineering done has to depend on the engineering technical college or go to industry and depend on industry, or work away for five years acquiring the knowledge and getting a research grant. By which time the problem has been forgotten or shelved or solved in some other way. This is a major issue which has got to 
be brought to light. When the National Health Service was introduced there was in actual fact little place for people doing this kind of thing. In this occupation they require some medical training and they require engineering skill and you just cannot get them at the moment except from industry. There is no other way of getting them because there is no such grade in the National Health Service. You will then have to give them the required position and a salary comparable to what they would get elsewhere. I do not know what the first speaker feels about this. He might support me on this.

\section{Mr. JoHn Bunyan:}

I agree there is just nowhere at the moment dealing with these problems. We formed this Trust because we could not think of any other way. As far as this kind of research is concerned, I think it needs to be done by individuals. The State cannot do it. The civil servant is not allowed to initiate things, and we cannot expect much initiation from the Ministry. No matter how much they want to, they cannot because of the whole way the thing is set up. We must rely on individual effort to deal with this. How you train these people I do not know. Perhaps by supporting something like our Trust. We want to show the way. This kind of thing and everything which involves inventive genius is something which just cannot be done elsewhere at the moment, and if we can get this thing so that it works we shall have shown the way round and done something useful in this country.

Mr. J. WALKER:

Mr. Chairman, I must refute that civil servants cannot do anything.

Mr. John Bunyan:

No, sir, I said that they cannot initiate anything. (Applause, laughter.)

Mr. J. WALKER:

I must refute that they cannot initiate anything. I was in industry before I entered Civil Service and I must confess that in my work for a large industrial organisation where I worked as an engineer before I joined the Civil Service-and now I have had four and a half years with the Ministry of Health-I have had more freedom to initiate things than I could possibly have had in industry. I do feel that if we are to give co-operation to continue development, that work on any problem which involves the National Health Service as a potential user or buyer, must be controlled by the Ministry in some form or other. I do not think that industry can be left to go in its own lines. It must not be let to run wild.

Mr. F. LoRD (Medical Engineer, Nuffield Department of Orthopaedic Surgery, Oxford):

I think I am a medical engineer. I listened with great interest this afternoon and was interested in the research that Mr. Bunyan has said something about. However, that is only one place and I should like to make it very clear that there are quite a number of us who are doing work on these specialist fittings. We may not know a lot about the construction, but we know a lot about what is required. We have many ideas, and in attending this Conference I hoped that something really constructive would come out of it. I should like to see the opportunity made for several of us who are working in this field to meet from time to time and to exchange ideas.

\section{Mr. JoHn BunYan:}

We are hoping that this will happen and it is in fact written into the Trust Deed that one of the functions of the Trust is to get people together at the centre. At the moment there is no work of this kind being done, so I hope you will write to me and we shall get together. 


\section{CHAIRMAN:}

My hope is that one of the far-reaching effects emerging from this discussion will be that something will be done in the future about the status and position of medical engineers. It is analogous to the earlier position in public helath. The public health engineer is a civil engineer who has a training that is partly of a medical character. He is a new figure in this country although there have been some of these people in the United States and the Continent for some years, and their professional status has been developed as the result of coming together and dealing with common problems, just as we are doing at this Conference. I feel that the more Conferences we have in which people of different disciplines but with common problems meet and exchange views freely, the more likely we are to proceed with the development of new training schemes and the promotion of new skills.

It now remains for me to thank Mr. Bunyan and Mr. Bickerstaff very warmly for their papers and all those who have participated in the discussion.

\section{Discussion on 'Prescription and Supply'}

\section{Chairman (Dr. Harvey Flack, M.D., Editor of The Family Doctor):}

Ladies and Gentlemen, we are now due to move on to the discussion of 'Prescription and Supply'. We have now two clinicians and we are going to hear the views that they take on this. Dr. Guttmann has been in the Chair all morning, as you know, and now we are going to hear him speak as one of the most distinguished clinicians particularly in the field of spinal injury.

With me on my right I have Dr. Millard, who is a consultant and is in charge of the Rehabilitation Centre of the North East Metropolitan Area at Clacton. He has also a very special interest in this field.

My own interest I can express briefly. I am the Editor of The Family Doctor and it will have been seen that we have an interest in wheelchairs and the users of the wheelchairs. One of my most effective colleagues is a woman, a doctor, who conducts her life very successfully from a wheelchair and has done so for the last ten years. She has brought up a substantial family and done a great deal of medical journalism and is a most valuable colleague. She has had to accept a wheelchair life and, like some of our speakers, she has not accepted that this should reduce her activities in any way except on some small physical points.

We became very interested in wheelchairs when I talked to Dr. N. F. R. Clyde, who, a former patient of the Stoke Mandeville Spinal Centre, was very active in the Disabled Drivers' Association in the early days. We published a major article on his wheelchair life. That was many years ago, but we still get requests for reprints of it. I have also had a closer personal interest because of my own nephew who is now twenty. He had a severe spinal injury at the age of twelve. He is now well and doing well and is immensely agile in getting himself in and out of his wheelchair and into his motorised tricycle. He owes his agility and skill and training, and indeed his life, to Dr. Guttmann and his colleagues at Stoke Mandeville.

I will first call on Dr. Millard.

\section{Dr. J. B. Millard (Director, Passmore Edward Rehabilitation Centre, Clacton):}

Everybody has said what I was going to say and a lot of common sense has been spoken today, but there are one or two things I will comment on.

What does the patient want? And what wheelchair does the patient need? That may please Mr. Denly. This is the answer, we have got to think of the patient, and we as doctors always start with the patient. I am a physical medicine consultant particularly interested in assessing the patient's ability. We have to assess why the patient needs a 